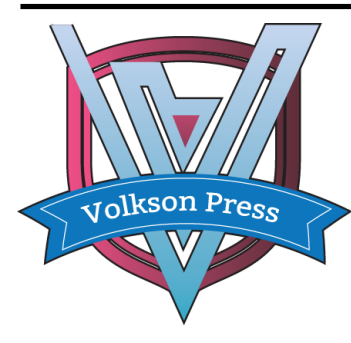

Contents List available at VOLKSON PRESS

New Materials and Intelligent Manufacturing (NMIM)

DOI : http://doi.org/10.26480/icnmim.01.2018.87.90

Journal Homepage: https://topicsonchemeng.org.my/

ISBN: 978-1-948012-12-6

\title{
DEFECT CHEMISTRY AND LOW-LOSS CHARACTERISTICS OF ND-DOPED BATIO3 DIELECTRIC CERAMICS
}

\author{
Dayong Lu*, Ji Lv, Xiuyun Sun \\ Key Laboratory for Special Functional Materials in Jilin Provincial Universities, Jilin Institute of Chemical Technology Chengde Street 45, Jilin
132022, China. \\ *Corresponding Author Email: dylu@jlict.edu.cn
}

This is an open access article distributed under the Creative Commons Attribution License, which permits unrestricted use, distribution, and reproduction in any medium, provided the original work is properly cited

\section{ARTICLE DETAILS}

\section{Article History:}

Received 26 June 2018 Accepted 2 July 2018

Available online 1 August 2018

\section{ABSTRACT}

$\left(\mathrm{Ba}_{1-x} \mathrm{Nd}_{x}\right) \mathrm{Ti}_{1-x / 4} \mathrm{O}_{3}(x=0.03-0.06)(\mathrm{BNT})$ ceramics with a single-phase perovskite structure were prepared using the mixed-oxides method. The structure, microstructure, point defects, defect chemistry, and dielectric properties of these ceramics were investigated using X-ray diffraction, scanning electron microscopy, electron paramagnetic resonance, and dielectric measurements. Except for BNT with $x=0.04$, all BNT ceramics are semiconductors because of the strong doping effect from A-site $\mathrm{Nd}^{3+}$. The defect chemistry is given. The highest concentrations of Ti vacancies and the intense reduction from $\mathrm{Mn}^{3+}$ or $\mathrm{Mn}^{4+}$ to $\mathrm{Mn}^{2+}$ as well as a small amount of Ba vacancies in BNT with $x=0.04$ are responsible for low dielectric loss $(<0.05)$ over the temperature range -50 to $150^{\circ} \mathrm{C}$.

\section{KEYWORDS}

Nd-doped $\mathrm{BaTiO}_{3}$ ceramics, X-ray diffraction, dielectric properties, defect chemistry, electron paramagnetic resonance

\section{INTRODUCTION}

In the dielectric field, Neodymium (Nd) is an effective rare-earth dopant in $\mathrm{BaTiO}_{3}$ ceramics. Nd-doped $\mathrm{BaTiO}_{3}$ ceramics with single substitution and with double substitutions have been widely investigated [1-9]. It is generally considered that $\mathrm{Nd}^{3+}$ is predominantly substituted for the $\mathrm{A}$-site, whereas a self-compensation model in $\left(\mathrm{Ba}_{1-x} \mathrm{Nd}_{x}\right)\left(\mathrm{Ti}_{1-x} \mathrm{Nd}_{x}\right) \mathrm{O}_{3}$ with $\mathrm{Ba} / \mathrm{Ti}=$ 1 and a slight amphoteric behavior of $\mathrm{Nd}^{3+}$ in $\left(\mathrm{Ba}_{1-x} \mathrm{Nd}_{x}\right)\left(\mathrm{Ti}_{1-x} \mathrm{Ho}_{x}\right) \mathrm{O}_{3}$ were discovered [1-9]. It is obvious that $\mathrm{Nd}^{3+}$ favors the $\mathrm{A}$-site over the $\mathrm{B}$-site because of its larger B-site ionic size (Table 1) [10]. However, the defect chemistry of $\mathrm{Nd}$-doped $\mathrm{BaTiO}_{3}$ ceramics has never reported.

Table 1: Ionic radii as a function of coordinate number (CN) [11].

\begin{tabular}{|lcc|}
\hline Ion & $\mathrm{CN}$ & $r(\AA)$ \\
\hline $\mathrm{Ba}^{2+}$ & 12 & 1.61 \\
$\mathrm{Ti}^{4+}$ & 6 & 0.605 \\
$\mathrm{Nd}^{3+}$ & 12 & 1.27 \\
$\mathrm{Nd}^{3+}$ & 6 & 0.983 \\
\hline
\end{tabular}

In this work, $\left(\mathrm{Ba}_{1-x} \mathrm{Nd}_{x}\right) \mathrm{Ti}_{1-x / 4} \mathrm{O}_{3}$ ceramics were prepared using a mixedoxide method. The defect chemistry is studied. It was found that the dielectric loss was depressed at $x=0.04$ in terms of the kinetic equilibrium of various defects.

\section{EXPERIMENTAL}

\subsection{Sample Preparation}

The initial materials were reagent-grade $\mathrm{BaCO}_{3}, \mathrm{TiO}_{2}$, and $\mathrm{Nd}_{2} \mathrm{O}_{3}$. BNT ceramics were prepared according to the nominal formula of $\left(\mathrm{Ba}_{1-}\right.$ $\left.{ }_{x} \mathrm{Nd}_{x}\right) \mathrm{Ti}_{1-x / 4} \mathrm{O}_{3}(x=0.03,0.04,0.05$, and 0.06$)$ using a conventional mixedoxide method. The well-mixed oxides were calcined at $1100^{\circ} \mathrm{C}$ for $5 \mathrm{~h}$. The mixtures with aqueous PVA were ground and pressed uniaxially at 200
MPa into disk-like pellets of $12 \mathrm{~mm}$ in diameter. The disks were heated at a rate of $100^{\circ} \mathrm{C} / \mathrm{h}$ and sintered at $1450^{\circ} \mathrm{C}$ for $24 \mathrm{~h}$ in air to form ceramics, and then furnace-cooled to room temperature (RT).

\subsection{Characterization}

Powder X-ray diffraction (XRD) patterns were measured at RT using a DX2700 X-ray diffractometer (Dandong Haoyuan). All XRD data were collected between $20^{\circ} \leq 2 \theta \leq 85^{\circ}$ in steps of $0.02^{\circ}$ and for 3 s per step. The lattice parameters and unit-cell volumes were calculated by a software package (Accelrys Inc.) using $\mathrm{Cu} \mathrm{K} \alpha_{1}$ radiation $(\lambda=1.540562 \AA)$. The microstructures were observed using a JSM-6330F scanning electron microscope (SEM, JEOL) operated at $15 \mathrm{kV}$. The average grain size (GS) was determined using Fullman's method [11]. The temperature dependences of the dielectric permittivity and the dielectric loss were measured at $1 \mathrm{kHz}$ from -75 to $200{ }^{\circ} \mathrm{C}$ at a heating rate of $2{ }^{\circ} \mathrm{C} / \mathrm{min}$ using a Concept 41 Dielectric/Impedance spectrometer (Novocontrol) with an applied voltage of $1 \mathrm{~V}$. Electron paramagnetic resonance (EPR) spectra were measured at RT using an A300 electron-spin resonance spectrometer system (Bruker BioSpin GMBH) at an X-band frequency of $9.86 \mathrm{GHz}$. The gyromagnetic factor $(g)$ was calculated by the relationship $h v_{0}=g \beta H$, where $h$ is the Planck constant $\left(h=6.626 \times 10^{-34} \mathrm{~J} \cdot \mathrm{s}\right), v_{0}$ is the microwave frequency, $\beta$ is the Bohr magneton $\left(\beta=9.262 \times 10^{-24} \mathrm{~J} / \mathrm{T}\right)$, and $H$ is the magnetic field strength.

\section{RESULTS AND DISCUSSION}

Powder XRD patterns of BNT ceramics are shown in Figure 1. BNT exhibited a tetragonal perovskite structure at $x \leq 0.04$ and a pseudo-cubic perovskite structure at $x \geq 0.05$. The miller indexes corresponding to the diffraction peaks of the tetragonal and cubic structures are given in Figure 1 (a). The $(002) /(200)$ peak splitting is characteristic of the tetragonal $\mathrm{BaTiO}_{3}$ (JCPDS cards No. 5-626). With the increase of $x$, it can be seen from Figure 1 (b) that two separate (002) and (200) peaks of BNT shift towards each other from 0.03 to 0.04 , indicating a decrease in tetragonality. As $x$ is increased to 0.05 , these two peaks are incorporated into a symmetric (200) peak characteristic of the cubic $\mathrm{BaTiO}_{3}$ (JCPDS cards No. 31-174). 
The variations in lattice parameters $(a, c)$ and unit-cell volume $\left(V_{0}\right)$ as functions of $x$ for BNT are shown in Fig. 2. The $V_{0}$ decreases with increasing $x$, following Vegard's law in the region from $x=0.03$ to 0.05 . On the basis of a comparison in 12-CN ionic size between $\mathrm{Ba}^{2+}(1.61 \AA)$ and $\mathrm{Nd}^{3+}(1.27$ $\AA$ ) and in 6-CN ionic size between $\mathrm{Ti}^{4+}(0.605 \AA)$ and $\mathrm{Nd}^{3+}(0.983 \AA)$, the decrease in $V_{0}$ provides evidence for the main occupations of the A-sites by $\mathrm{Nd}^{3+}[10]$. It is not easy for 6-CN Nd ${ }^{3+}(0.983 \AA$ Å) to enter B-site because of its lager ionic size as compared to $\mathrm{Ti}^{4+}$.
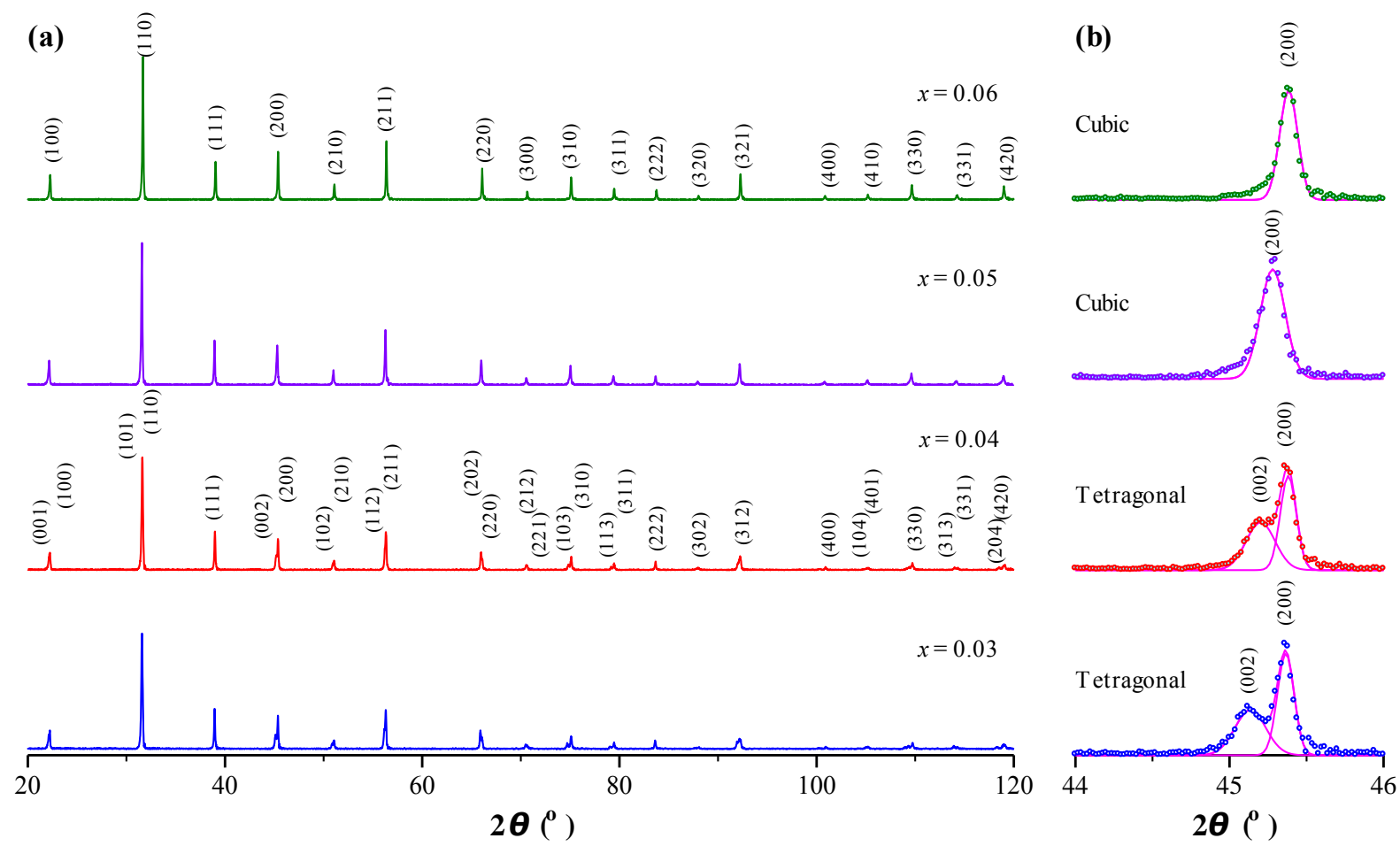

Figure 1: (a) Powder XRD patterns of $\left(\mathrm{Ba}_{1-x} \mathrm{Nd}_{x}\right) \mathrm{Ti}_{1-x / 4} \mathrm{O}_{3}(x=0.03-0.06)(\mathrm{BNT})$ ceramics sintered at $T_{\mathrm{s}}=1450{ }^{\circ} \mathrm{C}$. (b) Gaussian fitting to the peaks in the vicinity of $45^{\circ}$.

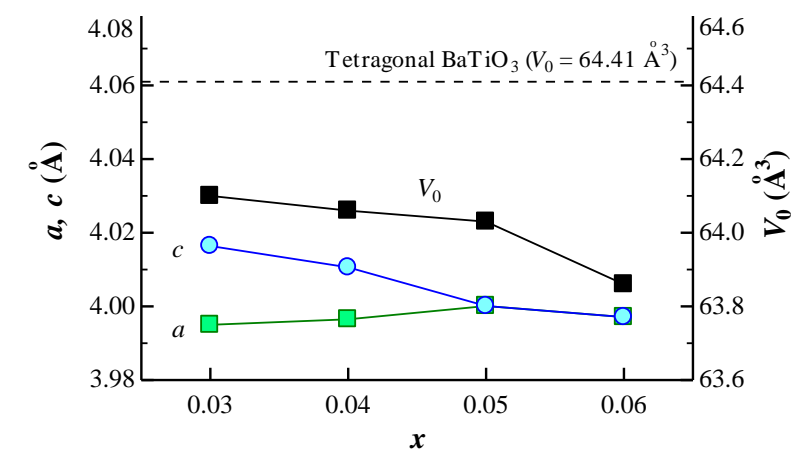

Figure 2: Variations in lattice parameters $(a, c)$ and unit-cell volume $\left(V_{0}\right)$ as functions of $x$ for BNT

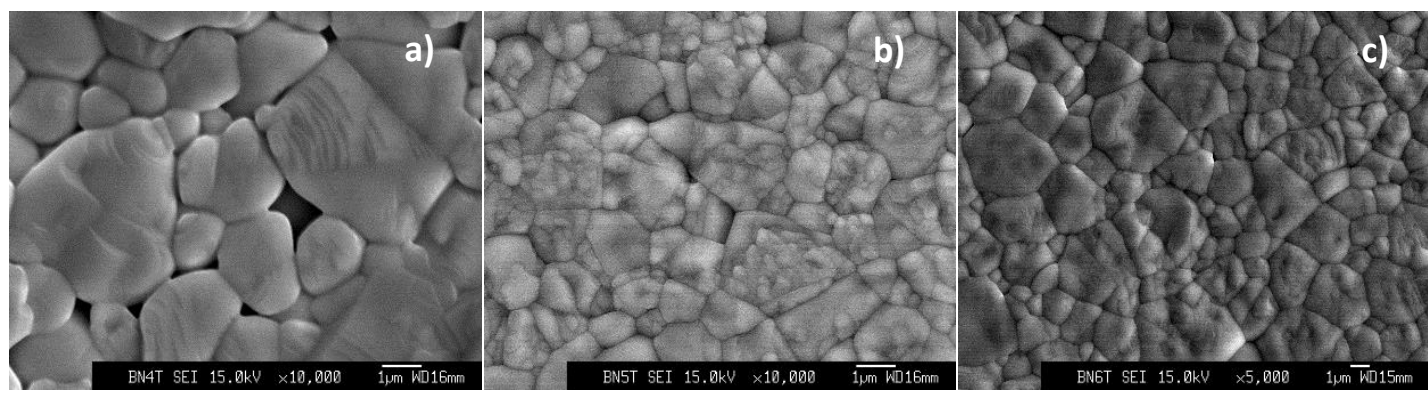

Figure 3: SEM images of the polished and thermally etched surfaces of BNT with $\mathrm{x}=(\mathrm{a}) 0.04$, (b) 0.05 , and (c) $=0.06$. 
The SEM images of BNT are shown in Figure 3. BNT exhibits a non-uniform microstructure, with an average grain size of $\sim 3 \mu \mathrm{m}$. This indicates that $\mathrm{Nd}$ doping in $\mathrm{BaTiO}_{3}$ cannot greatly suppress grain growth. The lamellar domain structures characteristic of ferroelectric phase were observed to exist in all BNT samples, as clearly observed at $x=0.04$. This fact reveals that the crystalline structure of BNT with $x \geq 0.05$ is pseudo-cubic.

The temperature dependences of the dielectric permittivity $\left(\varepsilon^{\prime}\right)$ and the

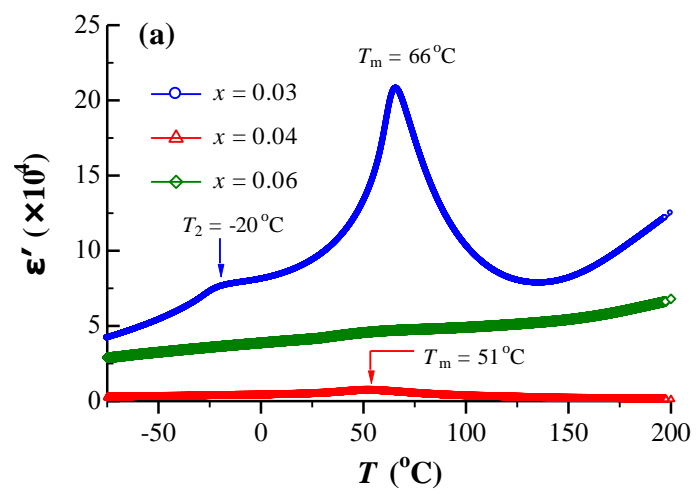

Figure 4: Temperature dependences of (a) $\varepsilon^{\prime}$ and (b) $\tan \delta$ at $1 \mathrm{kHz}$ for BNT with $\mathrm{x}=0.03,0.04$, and 0.06 . dielectric loss $(\tan \delta)$ for BPT are shown in Figure 4. The main dielectric peak corresponds to the tetragonal-cubic phase transition point. The dielectric-peak temperatures $\left(T_{\mathrm{m}}\right)$ are $66^{\circ} \mathrm{C}$ at $x=0.03$ and $51^{\circ} \mathrm{C}$ at $x=$ 0.04 , indicating a $T_{\mathrm{m}}$-shifting rate of $-15^{\circ} \mathrm{C} / \mathrm{at} . \% \mathrm{Nd}$. This rate is far lower than that reported by Shaikh and Vest $\left(-22^{\circ} \mathrm{C} /\right.$ at.\% $\left.\mathrm{Nd}\right)$ [5]. This suggests that some $\mathrm{Nd}^{3+}$ ions entered the B-sites except for dominant A-site substitutions, because $\mathrm{B}$-site occupations by $\mathrm{Nd}^{3+}$ will give rise to a much lower $T_{\mathrm{m}}$-shifting rate [6].

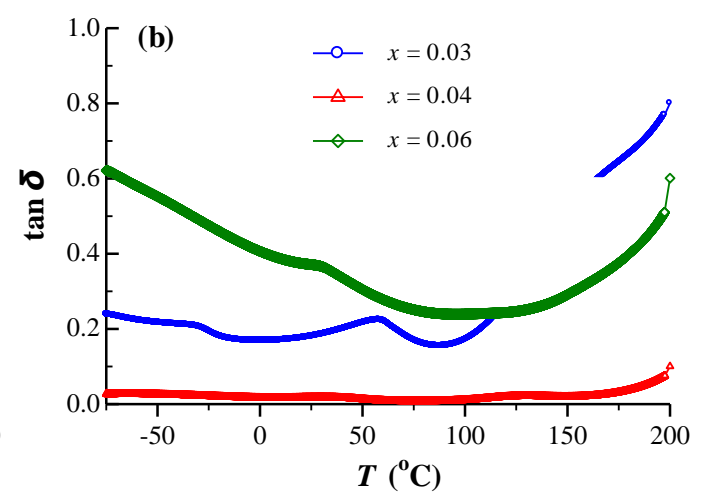

The $T_{2}$ corresponds to the orthorhombic-tetragonal phase transition point, indicating a decreased $T_{2}$ as compared to $\mathrm{BaTiO}_{3}\left(T_{2}=130{ }^{\circ} \mathrm{C}\right)$ [12]. This peak vanishes at $x \geq 0.04$, implying incomplete occupations by A-site $\mathrm{Nd}^{3+}$. BNT ceramics with $x=0.03$ and $x \geq 0.05$ are semiconductors because of their high values of $\tan \delta>0.15$. Their semi-conducting nature arises from the strong doping effect from A-site $\mathrm{Nd}^{3+}$, which relates to a higher sintering temperature of $1400^{\circ} \mathrm{C}$ and long-term sintering for $24 \mathrm{~h}$. The $x=$ 0.04 sample exhibits a higher room-temperature permittivity of $\varepsilon_{\mathrm{RT}}^{\prime}=$ 6955 and a lower $\tan \delta(<0.05)$ over the temperature range -50 to $150^{\circ} \mathrm{C}$ (Figure 5). The sample is not a semiconductor, rather than a common ferroelectric.

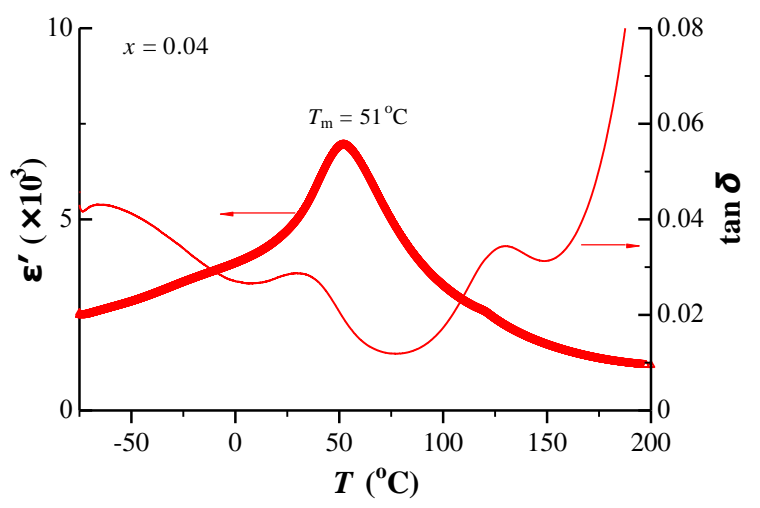

Figure 5: Enlarged $\varepsilon^{\prime}-\mathrm{T}$ and $\tan \delta-\mathrm{T}$ curves for BNT with $\mathrm{x}=0.04$.

To understand the origin of lower $\tan \delta$ of BNT with $x=0.04$, the EPR spectra of all BNT samples was measured, as shown in Fig. 6. Three EPR signals were observed at $x=0.03$. A sextet signal arises from $\mathrm{Mn}^{2+}$ impurities existing in ceramics. The second and third ones at $g=2.004$ and 1.974 originates from ionized Ti-vacancy $\left(\mathrm{V}_{\mathrm{Ti}}\right)$ and Ba-vacancy $\left(\mathrm{V}_{\mathrm{Ba}}\right)$,

respectively [13-15]. As $x$ is increased to 0.04 , the intensity of both $\mathrm{V}_{\mathrm{Ti}^{-}}$ related and $\mathrm{Mn}^{2+}$ signals evidently increases, whereas that of the $\mathrm{V}_{\mathrm{Ba}}-$ related signal decreases and subsequently it disappears at $x \geq 0.05$; at the same time, both $\mathrm{V}_{\mathrm{Ti}}$-related and $\mathrm{Mn}^{2+}$ signals become very weak.

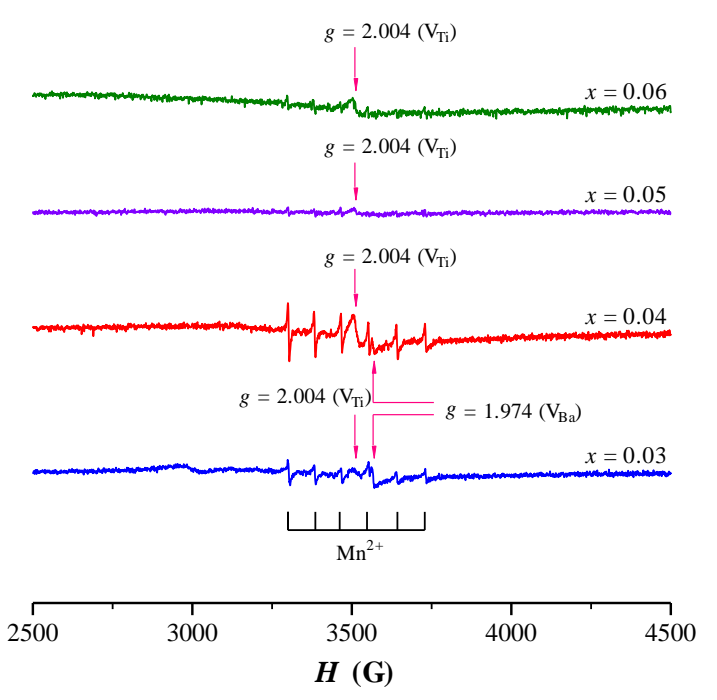

Figure 6: EPR spectra of BNT, measured at room temperature.

On the basis of nominal compositions $\left(\mathrm{Ba}_{1-x} \mathrm{Nd}_{x}\right) \mathrm{Ti}_{1-x / 4} \mathrm{O}_{3}$, the persistent existence of $\mathrm{V}_{\mathrm{Ti}}$ implies dominant occupations of the A-sites by $\mathrm{Nd}^{3+}$ in BNT, which can not only contribute to creation of $\mathrm{V}_{\mathrm{Ti}}$ (Eq. (1)) but also to the unwelcome doping effect (Eq. (2)).

$$
\begin{aligned}
& 2 \mathrm{Nd}_{2} \mathrm{O}_{3}+3 \mathrm{TiO}_{2} \rightarrow 4 \mathrm{Nd}_{\mathrm{Ba}}^{\bullet}+3 \mathrm{Ti}_{\mathrm{Ti}}+\mathrm{V}_{\mathrm{Ti}}^{\mathrm{\prime \prime \prime}}+12 \mathrm{O}_{\mathrm{O}} \\
& \mathrm{Nd}_{2} \mathrm{O}_{3}+2 \mathrm{TiO}_{2} \rightarrow 2 \mathrm{Nd}_{\mathrm{Ba}}^{\bullet}+2 \mathrm{Ti}_{\mathrm{Ti}}+6 \mathrm{O}_{\mathrm{O}}+1 / 2 \mathrm{O}_{2}+2 \mathrm{e}^{\prime}
\end{aligned}
$$

Defect notation proposed by Kröger and Vink are adopted [16].

In $\mathrm{BaTiO}_{3}$-based ceramics, $\mathrm{Mn}$ impurities generally exist in the high valence states of $\mathrm{Mn}^{3+}$ or $\mathrm{Mn}^{4+}$. The reduction from $\mathrm{Mn}^{3+}$ or $\mathrm{Mn}^{4+}$ to $\mathrm{Mn}^{2+}$ induced by the $\mathrm{Nd}^{3+}$ doping plays an important role in trapping electrons created by the doping effect (Eq. (1)) and therefore can reduce the dielectric loss.

$$
\begin{aligned}
& \mathrm{Mn}_{\mathrm{Ti}}^{\times}+2 \mathrm{e}^{\prime} \rightarrow \mathrm{Mn}_{\mathrm{Ti}}^{\prime \prime} \\
& \mathrm{Mn}_{\mathrm{Ti}}^{\prime}+\mathrm{e}^{\prime} \rightarrow \mathrm{Mn}_{\mathrm{Ti}}^{\prime \prime}
\end{aligned}
$$




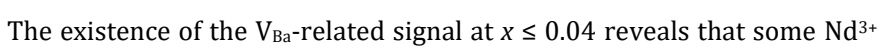
ions transfer from A-sites to B-sites, in accordance with the dielectric behavior.

$$
3 \mathrm{BaO}+\mathrm{Nd}_{2} \mathrm{O}_{3}+2 \mathrm{TiO}_{2} \rightarrow 3 \mathrm{Ba}_{\mathrm{Ba}}+\mathrm{V}_{\mathrm{Ba}}^{\prime \prime}+2 \mathrm{Nd}_{\mathrm{Ti}}^{\prime}+2 \mathrm{Ti}_{\mathrm{Ti}}+12 \mathrm{O}_{\mathrm{O}}
$$

The point defects in BNT with $x=0.04$ are A-site $\mathrm{Nd}^{3+}\left(\mathrm{Nd}_{\mathrm{Ba}}^{\bullet}\right)$, Ba vacancies $\left(\mathrm{V}_{\mathrm{Ba}}^{\prime \prime}\right)$, B-site $\mathrm{Nd}^{3+}\left(\mathrm{Nd}_{\mathrm{Ba}}^{\prime}\right)$, and Ti vacancies $\left(\mathrm{V}_{\mathrm{Ti}}^{\prime \prime \prime \prime}\right)$. This sample has the highest concentrations of $\mathrm{Ti}$ vacancies and $\mathrm{Mn}^{2+}$ as well as a small amount of Ba vacancies, which are responsible for its low dielectric loss.

\section{CONCLUSIONS}

The nominal $\left(\mathrm{Ba}_{1-x} \mathrm{Nd}_{x}\right) \mathrm{Ti}_{1-x / 4} \mathrm{O}_{3}(x=0.03-0.06)$ ceramics were prepared at $1450{ }^{\circ} \mathrm{C}$ for $24 \mathrm{~h}$ in air using the mixed-oxide method. BNT exhibited a tetragonal perovskite structure at $x \leq 0.04$ and a pseudo-cubic perovskite structure at $x \geq 0.05$. BNT with $x=0.03$ and $x \geq 0.05$ are semiconductors because of the strong doping effect from A-site $\mathrm{Nd}^{3+}$. The defect chemistry is given. BNT with $x=0.04$ is a common ferroelectric, showing higher $\varepsilon_{\mathrm{RT}}^{\prime}$ $(=6955)$ and lower $\tan \delta(<0.05)$ over the temperature range -50 to $150{ }^{\circ} \mathrm{C}$; the highest concentrations of $\mathrm{Ti}$ vacancies and the intense reduction from $\mathrm{Mn}^{3+}$ or $\mathrm{Mn}^{4+}$ to $\mathrm{Mn}^{2+}$ as well as a small amount of $\mathrm{Ba}$ vacancies are responsible for low dielectric loss.

\section{ACKNOWLEDGMENTS}

This work was supported by the projects of the National Natural Science Foundations of China (21271084) and of Jilin Province (20160101290JC), and Changbai Mountain Scholar Distinguished Professor (2015047).

\section{REFERENCES}

[1] Liu, Q., Liu, J., Lu, D., Zheng, W. 2018. Colossal dielectric behavior and relaxation in Nd-doped $\mathrm{BaTiO}_{3}$ at low temperature. Ceramics International, 44 (6), 7251-7258.

[2] Jena, H., Mittal, V.K., Bera, S., Narasimhan, S.V., Govindan Kutty, K.V., Kutty T.R.N. 2008. X-ray photoelectron spectroscopic investigations on cubic $\mathrm{BaTiO}_{3}, \mathrm{BaTi}_{0.9} \mathrm{Fe}_{0.1} \mathrm{O}_{3}$ and $\mathrm{Ba}_{0.9} \mathrm{Nd}_{0.1} \mathrm{TiO}_{3}$ systems. Applied Surface Science, 254 (21), 7074-7079.

[3] Yao, Z., Liu, H., Liu, Y., Wu, Z., Shen, Z., Liu, Y., Cao, M. 2008. Structure and dielectric behavior of $\mathrm{Nd}$-doped $\mathrm{BaTiO}_{3}$ perovskites. Materials Chemistry and Physics, 109 (2-3), 475-481.
[4] Kutty, T.R.N., Murugaraj, P. 1987. Phase relations and dielectric properties of $\mathrm{BaTiO}_{3}$ ceramics heavily substituted with neodymium. Journal of Materials Science, 22, 3652-3664.

[5] Shaikh, A.S., Vest, R.W. 1986. Defect structure and dielectric properties $\mathrm{Nd}_{2} \mathrm{O}_{3}$-modified $\mathrm{BaTiO}_{3}$. Journal of the American Ceramic Society, 69 (9), 689-694.

[6] Hirose, N., Skakle, J.M.S., West, A.R. 1999. Doping mechanism and permittivity correlations in $\mathrm{Nd}$-doped $\mathrm{BaTiO}_{3}$. Journal of Electron ceramics, 3, 233-238.

[7] Ghosh, S.K., Ganguly, M., Rout, S.K., Chanda, S., Sinha, T.P. 2014. Structural, optical and dielectric relaxor properties of neodymium doped cubic perovskite $\left(\mathrm{Ba}_{1-x} \mathrm{Nd}_{2 x / 3}\right)\left(\mathrm{Zr}_{0.3} \mathrm{Ti}_{0.7}\right) \mathrm{O}_{3}$. Solid State Science, 30, 68-77.

[8] Wei, M., Zhang, J., Wu, K., Chen, H., Yang, C. 2017. Effect of $\mathrm{BiMO}_{3}(\mathrm{M}=\mathrm{Al}, \mathrm{In}, \mathrm{Y}, \mathrm{Sm}, \mathrm{Nd}$, and La) doping on the dielectric properties of $\mathrm{BaTiO}_{3}$ ceramics. Ceramics International, 43 (13), 9593-9599.

[9] Lu, D., Guan, D., Li, H. 2018. Multiplicity of photoluminescence in Raman spectroscopy and defect chemistry of $\left(\mathrm{Ba}_{1-x} R_{x}\right)\left(\mathrm{Ti}_{1-x} \mathrm{Ho}_{x}\right) \mathrm{O}_{3}(R=\mathrm{La}, \mathrm{Pr}, \mathrm{Nd}$ $\mathrm{Sm})$ dielectric ceramics. Ceramics International, 44 (2), 1483-1492.

[10] Shannon, R.D. 1976. Revised effective ionic radii and systematic studies of interatomic distances in halides and chalcogenides. Acta Crystallogr. Sect A 32, 751-767.

[11] Dieter, G.E. 1988. Mechanical Metallurgy. London, McGraw-Hill.

[12] Lu, D., Toda, M., Sugano, M. 2006. High-permittivity double rareearth-doped barium titanite ceramics with diffuse phase transition. Journal of the American Ceramic Society, 89 (10), 3112-3123.

[13] Kolodiazhnyi, T., Petric, A. 2003. Analysis of point defects in polycrystalline $\mathrm{BaTiO}_{3}$ by electron paramagnetic resonance, Journal of Physics and Chemistry of Solids, 64, 953-960.

[14] Dunber, T.D., Warren, W.L., Tuttle, B.A., Randall, C.A., Tsur, T. 2004. Electron paramagnetic resonance investigation of lanthanide-doped barium titanate: dopant site occupancy. The Journal of Physical Chemistry B, 108, 908-917.

[15] Lu, D., Cui, S. 2014. Defects characterization of Dy-doped $\mathrm{BaTiO}_{3}$ ceramics via electron paramagnetic resonance. Journal of European Ceramic Society, 34 (10), 2217-2227.

[16] Kröger, F.A., Vink, H.J. 1956. Relations between the Concentrations of Imperfections in Crystalline Solids. In Seitz, F. \& Turnbull, D. (Eds.), Solid State Physics (p. 307). New York: Academic Press. 